\title{
Epilepsy and hypertension: The possible link for sudden unexpected death in epilepsy?
}

\author{
Patrycja J. Szczurkowska ${ }^{1}$, Katarzyna Polonis ${ }^{1,2}$, Christiane Becari ${ }^{3}$, \\ Michał Hoffmann ${ }^{1}$, Krzysztof Narkiewicz ${ }^{1}$, Marzena Chrostowska ${ }^{1}$ \\ ${ }^{1}$ Department of Hypertension and Diabetology, Medical University of Gdansk, Poland \\ ${ }^{2}$ Center for Individualized Medicine, Mayo Clinic, Rochester, MN, United States \\ ${ }^{3}$ Department of Surgery and Anatomy, Ribeirao Preto Medical School, Ribeirão Preto-SP, Brazil
}

\begin{abstract}
Epilepsy affects about 50 million people worldwide. Sudden unexpected death in epilepsy (SUDEP) is the main cause of death in epilepsy accounting for up to $17 \%$ of all deaths in epileptic patients, and therefore remains a major public health problem. SUDEP likely arises from a combination and interaction of multiple risk factors (such as being male, drug resistance, frequent generalized tonic-clonic seizures) making risk prediction and mitigation challenging. While there is a general understanding of the physiopathology of SUDEP, mechanistic hypotheses linking risk factors with a risk of SUDEP are still lacking. Identifying cross-talk between biological systems implicated in SUDEP may facilitate the development of improved models for SUDEP risk assessment, treatment and clinical management. In this review, the aim was to explore an overlap between the pathophysiology of hypertension, cardiovascular disease and epilepsy, and discuss its implication for SUDEP. Presented herein, evidence in literature in support of a cross-talk between the renin-angiotensin system (RAS) and sympathetic nervous system, both known to be involved in the development of hypertension and cardiovascular disease, and as one of the underlying mechanisms of SUDEP. This article also provides a brief description of local RAS in brain neuroinflammation and the role of centrally acting $R A S$ inhibitors in epileptic seizure alleviation. (Cardiol J 2021; 28, 2: 330-335)
\end{abstract}

Key words: hypertension, epilepsy, SUDEP, cardiovascular diseases, renin-angiotensin system, neuroinflammation

\section{Introduction}

Epilepsy with its comorbidities such as depression and anxiety significantly affect quality of life. Importantly, mortality rates in epileptics are greatly higher than that of the general population [1], and sudden unexpected death in epilepsy (SUDEP), known as a seizure related event, is the main cause of death in those patients. The etiology of SUDEP remains unclear. Effective seizure control was shown to be a preventive strategy for premature death in epilepsy [2], however, approximately $30 \%$ of patients do not respond to treatment with common anticonvulsants [3].
Epileptic seizures result from uncontrollable neuronal excitation in the brain; therefore, epilepsy is considered to be a neuronal disease. However, recent investigations indicate that the model of epileptogenesis could be more complex. The evidence that seizure increases levels of inflammatory mediators in brain suggests that cytokines and prostaglandins could be therapeutic targets for new antiepileptic drugs [4]. Experimental studies on animal models of epilepsy showed that local renin-angiotensin system (RAS) in the brain is involved in neuroinflammation and administration of common antihypertensive drugs, such as angiotensin II receptor blocker (ARB) that crosses the

Address for correspondence: Dr. Marzena Chrostowska, Department of Hypertension and Diabetology,

Medical University of Gdansk, ul. Dębinki 7, 80-211 Gdańsk, Poland, tel: +58 34925 27, tel./fax: +58 3492503 ,

e-mail: marzena.chrostowska@gumed.edu.pl

Received: 15.02.2019 Accepted: 26.06.2019

This article is available in open access under Creative Common Attribution-Non-Commercial-No Derivatives 4.0 International (CC BY-NC-ND 4.0) license, allowing to download articles and share them with others as long as they credit the authors and the publisher, but without permission to change them in any way or use them commercially. 
brain barrier, reduces blood pressure and attenuated neuronal injury $[3,5]$.

In the current literature a few review papers targeting the possible pathophysiology mechanism of SUDEP, but no one has confronted hypertension with epilepsy. Some interesting original articles present studies conducted on animal models with hypertension and epilepsy, suggesting the overlap between hypertension and epilepsy pathophysiology.

The aim of this review is to present pathophysiological and clinical aspects of hypertension, cardiovascular diseases (CVD) and epilepsy and to explore the possibility that these disorders are related to each other.

This review advances the hypothesis that components of RAS in association with sympathetic activity may play a crucial role in the patomechanism of SUDEP. Evidence in the literature is presented that shows RAS inhibitors may be used to potentially alleviate epileptic seizures and build a hypothesis that targeting RAS may also reduce the risk of SUDEP.

\section{Epilepsy and SUDEP}

Epilepsy is a neurological disease characterized by recurrent seizures resulting from abnormal excessive or synchronous activity in brain [6]. An imbalance between excitation and inhibition in the brain, the basis of this phenomenon, results from alterations at many levels of brain functioning, neuronal circuits, and genetic predisposition [7]. Epilepsy diagnosis requires the presence of at least one unprovoked seizure in a patient who has other factors associated with high recurrence risk of latter seizures $[1,6]$. Depending on the character of the onset, seizures are classified as focal or generalized, with motor or nonmotor onset [8]. Status epilepticus (SE) is defined as 5 min of ongoing seizure activity to diagnose convulsive SE (bilateral tonic-clonic SE) and $10 \mathrm{~min}$ for focal or absence SE [9].

Every hundredth person suffers from epilepsy and in about one-third of those patients, refractory epilepsy is recognized [7]. Importantly, the risk of premature death in patients with epilepsy is about 2-3 times higher than the general population [1].

Sudden unexpected death in eplilepsy accounts for up to $17 \%$ of deaths in patients with epilepsy [10]. SUDEP is defined as a sudden, unexpected, witnessed or unwitnessed, non-traumatic and non-drowning death in patients with epilepsy, with or without evidence of a seizure excluding documented status epilepticus, in which postmor- tem examination does not reveal a toxicological or anatomical cause of death [11]. SUDEP incidence is estimated to be from 0.3 to 6 persons per 1000 adult person-years [2]; however, SUDEP may be under-diagnosed due to the fact that the $10^{\text {th }}$ revision of International Classification of Disease does not include term SUDEP as a cause of death $[1,10]$.

There are still limited tools to stratify individual risk for SUDEP [12]. A number of risk factors have been reported to be associated with SUDEP, including general tonic-clonic seizures and poor seizure control, young onset and long duration of epilepsy, and young age [11]. It is estimated that young adults (aged 20-45 years) have 27.5 higher risk of SUDEP than the general population [13]. The reasons for the increased incidence of SUDEP in early adulthood are unknown, therefore a better understanding of underlying pathophysiology is crucial for treatment and SUDEP prevention [10].

\section{Pathomechanism of SUDEP: Sympathetic system and heart}

Sudden unexpected death in epilepsy is proposed to result from the accumulation of disturbances in numerous biological systems such as the cardiac, respiratory, and nervous systems [11]. MORTEMUS study suggested that impaired respiratory function may play a crucial role in this condition based on the fact that terminal apnea always preluded terminal asystole in epileptic patients who died unexpectedly [14]. In addition, the brainstem arousal system dysfunction and dysregulation in the neurotransmitter and neuromodulator system are mechanisms that presumably take part in the pathogenesis of SUDEP [12].

Seizure affects cardiac function which may lead to Takotsubo syndrome, cardiomyocyte injury, arterial hypertension and probably even premature death in epileptic patients [15]. Clinical data suggest that there is a resemblance between SUDEP and sudden cardiac deaths such as both unexpected events are characterized by abrupt loss of consciousness [16]. Sudden cardiac deaths occur mostly in the morning when the patient is awake, while SUDEP mostly when patient is asleep in a prone position [12]. Ruthirago at al. [10] suggested that some cases of SUDEP could be misinterpreted as sudden cardiac deaths, cardiorespiratory failure or sudden infant death syndrome, especially in patients without prior diagnosis of epilepsy.

Seizures affect central autonomic system and as a result may alter pulmonary and cardiovascular functions which are linked with the risk of 
SUDEP [17]. Refractory epilepsy is accompanied by increased sympathetic tone and reactivity and decreased parasympathetic tone and reactivity [15]. More than $90 \%$ cases of seizure are associated with increased heart rate, suggesting that cardiac dysfunction is strongly related to chronic, refractory epilepsy [18]. According to Powell et al. [19], chronic epilepsy contributes to channelopathy, that can result in fatal arrhythmias. Electrocardiographic abnormalities, including repolarization alteration, are found in individuals with a long history of epilepsy. ST segment depression was described to occur during and just after the seizure. QT lengthening was also observed in an association with electroencephalographic discharges, especially in those patients who have later died from SUDEP [20].

Importantly, anticonvulsants may also trigger SUDEP by facilitating the occurrence of severe cardiac arrhythmias via altering cardiac conduction and the length of QT interval. Interestingly, an abrupt antiepileptic drugs withdrawal results in increased sympathetic tone and therefore could create conditions for sudden, unexpected death [3, 11, 21].

\section{Prevalence of hypertension with the focus on young population}

Hypertension affects $30-45 \%$ adults worldwide [22]. The incidence of arterial hypertension is projected to increase by $15-20 \%$ by 2025 as a consequence of an aging population and the obesity epidemic [22].

The prevalence of hypertension in a group of adults aged $18-39$ is $7.3 \%$, the majority are men. This group of patients is less likely to have controlled hypertension than those aged 60 and over [23]. Clinical data demonstrated that young adults with documented elevated blood pressure have slower rates of antihypertensive medication initiation than older patients. Importantly, uncontrolled hypertension, both in young and older populations, increases the risk of future cardiovascular events [24].

\section{Hypertension mediated organ damage: The role of RAS and sympathetic system}

Untreated or poorly controlled hypertension is associated with structural and/or functional changes in heart, blood vessels, brain, eyes and kidneys, which are markers of asymptomatic CVD [22]. The role of systemic RAS is classically recognized in the regulation of cardiovascular homeostasis. RAS plays a critical role in the pathophysiology of hypertension, and therefore in the development of hypertension-related target organ damage [25]. A growing body of evidence shows that circulating RAS does not act independently, but in cooperation with local RAS in different tissues and organs [26]. The extent of local RAS contribution to cardiovascular complications remains unknown [26].

The activated RAS is associated with the altered expression and distribution of its components, with the main focus on angiotensin II (Ang II) and its receptor angiotensin II type 1 receptor (AT1), the strongest element of RAS [26]. Overactivity of AT1 receptor has been demonstrated to be associated with vascular remodeling, endothelial dysfunction and accelerated arterial stiffening [27]. Conversely, angiotensin-converting enzyme inhibitors (ACEI) and AT1 receptor blockers have been shown to prevent tissue damage. Conceivably, the beneficial effect of ACEI and AT1 receptors may be attributed to both systemic and local RAS blockage/ /inhibition [25].

An overactive sympathetic nervous system (SNS) is characteristic for CVD including hypertension and hypertension-related organ damage, such as left ventricular hypertrophy, renal dysfunction or arteriolar remodeling [28]. Many studies suggest that the RAS might be a link between sympathetic nervous system activity and hypertension [29].

It has been shown that SNS affects the release of renin from the kidneys. Ang II, a crucial effector of RAS which acts by binding to AT1 receptors on sympathetic nerve endings, induces SNS activity by enhancing norepinephrine release [26]. Taken altogether, it suggests that inhibition of RAS contributes to decreased SNS activity and alleviated organ complications.

\section{Hypertension and epilepsy}

According to the study presented by Wilner et al. [30], on a group of patients older than 19 years with epilepsy, hypertension was the most common comorbid condition. This observation suggests that hypertension may play an important role in epilepsy.

The association between hypertension and epilepsy seems to be bidirectional. The cerebral damage resulting from high blood pressure could lower seizure threshold and therefore cause epilepsy [31]. Thus, chronic hypertension contributes to late onset of seizure [32]. On the other hand, seizure onset is connected with increased sympathetic tone. That could lead by itself to increased blood pressure. Hypertension as a frequent, sometimes severe comorbid condition, and may be complicated 
by posterior reversible encephalopathy syndrome in some cases [20].

\section{Brain RAS and neuroinflammation}

The brain RAS is involved in body water balance, maintenance of blood pressure, cyclicity of reproductive hormones and sexual behaviors, and regulation of releasing pituitary gland hormones [33]. A growing body of evidence suggests the role of neuroinflammation in the pathology of epilepsy, as it has been shown, is the association with the occurrence of seizure and generation of pathological lesions after seizure [34]. According to Sun et al. [5], the expression of Ang II peptide substantially increased in activated microglia after seizure. Ang II and its AT1 receptor amplify neuroinflammatory reaction, that in turn contribute to neurodegeneration. Subsequently, the inhibition of AT1 receptor may result in reduced inflammatory response and decreased levels of oxidative stress. In epilepsy RAS inhibitors may act as anti-inflammatory and neuroprotective agents. Experimental studies have also shown that blockade of AT1 receptor reduced the infarct volume after ischemia in rats. The neuroinflammation in the hippocampus is strongly associated with activated microglia and cognitive impairment in epileptic patients $[5,35$, 36]. Interestingly, it has been reported that ACEI can attenuate neuroinflammation and prevent neuronal loss in the hippocampus during epilepsy [37]. Contrary to Ang II, the axis Ang 1-7/Mas receptor is involved in attenuation of the inflammatory process. Anti-inflammatory action can also exist in the brain and may play an important role in epilepsy [38].

\section{RAS inhibitors alleviate epileptic seizure}

Hippocampus is recruited in the most common type of epilepsy - temporal lobe epilepsy [34]. Rat epilepsy models showed that seizures were associated with increased expression of ACE and AT1 receptor in the temporal lobe epilepsy. In turn, treatment with ACEI substantially reduced limbic and tonic-clonic seizure severity without affecting blood pressure [3, 31, 39]. ARB treatment was associated with not only seizure suppression, but also systolic blood pressure reduction [3].

Other studies have revealed that pilocarpine-induced acute and silent phase of experimental status epilepticus was associated with a high concentration of Ang 1-7 peptides. This observation was attributed to the response to injury and the anti-inflammatory effects of Ang 1-7. The chronic period (which started with the first spontaneous seizure, after the acute and silent phase) was associated with higher levels of Ang II peptides contrary to the acute and silent phase, which was accompanied with its lower concentrations. The expression of tonin mRNA, element of local RAS, an alternative pathway to Ang II generation from angiotensinogen, were significantly increased [40].

Angiotensin II receptor blockers have been shown to affect transforming growth factor (TGF)beta signaling pathway. This cytokine is associated with vascular injury in the brain e.g. after stroke and trauma, and thus may play a crucial role in epileptogenesis. Losartan effectively blocked TGF-beta activation in the brain and in this way acted as antiepileptic drug in the animal model of acquired epilepsy [39]. The potential neuroprotective effects of RAS targeted drugs were demonstrated by a study showing that administration of losartan (ARB) led to essential delays in the occurrence of seizure, shorten seizure duration and frequency in the animal model of epilepsy [31]. There is a need for further investigation on this underlying mechanism.

\section{Conclusions}

A better understanding of SUDEP is needed to develop effective prevention strategies. In this review, compelling evidence is presented describing the link between hypertension, brain RAS, sympathetic system and epilepsy. Based on evidence from literature it is hypothesized that targeting RAS may be an effective strategy to reduce epileptic seizure in humans and potentially reduce the risk of SUDEP.

\section{Acknowledgements}

Christiane Becari was supported by Fundação de Amparo à Pesquisa do Estado de São Paulo, Brazil (FAPESP 2017/21539-7; 2018/23718-8).

\section{Conflict of interest: None declared}

\section{References}

1. Zhuo L, Zhang Y, Zielke HR, et al. Sudden unexpected death in epilepsy: Evaluation of forensic autopsy cases. Forensic Sci Int. 2012; 223(1-3): 171-175, doi: 10.1016/j.forsciint.2012.08.024, indexed in Pubmed: 22999232.

2. Manolis TA, Manolis AA, Melita H, et al. Sudden unexpected death in epilepsy: The neuro-cardio-respiratory connection. Seizure. 2019; 64: 65-73, doi: 10.1016/j.seizure.2018.12.007, indexed in Pubmed: 30566897. 
3. Pereira MG, Becari C, Oliveira JAC, et al. Inhibition of the renin-angiotensin system prevents seizures in a rat model of epilepsy. Clin Sci (Lond). 2010; 119(11): 477-482, doi: 10.1042/ CS20100053, indexed in Pubmed: 20533906.

4. Shimada T, Takemiya T, Sugiura H, et al. Role of inflammatory mediators in the pathogenesis of epilepsy. Mediators Inflamm. 2014; 2014: 901902, doi: 10.1155/2014/901902, indexed in Pubmed: 25197169.

5. Sun $\mathrm{H}, \mathrm{Wu} \mathrm{H}, \mathrm{Yu} \mathrm{X}$, et al. Angiotensin II and its receptor in activated microglia enhanced neuronal loss and cognitive impairment following pilocarpine-induced status epilepticus. Mol Cell Neurosci. 2015; 65: 58-67, doi: 10.1016/j.mcn.2015.02.014, indexed in Pubmed: 25724109.

6. Fisher RS, Acevedo C, Arzimanoglou A, et al. ILAE official report: a practical clinical definition of epilepsy. Epilepsia. 2014; 55(4): 475-482, doi: 10.1111/epi.12550, indexed in Pubmed: 24730690.

7. Stafstrom C, Carmant L, et al. Seizures and epilepsy: An overview for neuroscientists. Cold Spring Harb Perspect Med. 2015; 5(6): 1-18.

8. Fisher RS, Cross JH, French JA, et al. Operational classification of seizure types by the International League Against Epilepsy: position paper of the ILAE Commission for Classification and Terminology. Zeitschrift fur Epileptol. 2018; 31(4): 272-281.

9. Leitinger M, Trinka E, Giovannini G, et al. Epidemiology of status epilepticus in adults: A population-based study on incidence, causes, and outcomes. Epilepsia. 2019; 60(1): 53-62, doi: 10.1111/epi.14607, indexed in Pubmed: 30478910.

10. Ruthirago D, Julayanont P, Karukote A, et al. Sudden unexpected death in epilepsy: ongoing challenges in finding mechanisms and prevention. Int J Neurosci. 2018; 128(11): 1052-1060, doi: 10.1080/00207454.2018.1466780, indexed in Pubmed: 29667458.

11. Surges R, Thijs RD, Tan HL, et al. Sudden unexpected death in epilepsy: risk factors and potential pathomechanisms. Nat Rev Neurol. 2009; 5(9): 492-504, doi: 10.1038/nrneurol.2009.118, indexed in Pubmed: 19668244.

12. Devinsky O, Hesdorffer DC, Thurman DJ, et al. Sudden unexpected death in epilepsy: epidemiology, mechanisms, and prevention. Lancet Neurol. 2016; 15(10): 1075-1088, doi: 10.1016/ S1474-4422(16)30158-2, indexed in Pubmed: 27571159.

13. Holst AG, Winkel BoG, Risgaard B, et al. Epilepsy and risk of death and sudden unexpected death in the young: a nationwide study. Epilepsia. 2013; 54(9): 1613-1620, doi: 10.1111/epi.12328, indexed in Pubmed: 23895621.

14. Ryvlin P, Nashef L, Lhatoo SD, et al. Incidence and mechanisms of cardiorespiratory arrests in epilepsy monitoring units (MORTEMUS): a retrospective study. Lancet Neurol. 2013; 12(10): 966-977, doi: 10.1016/S1474-4422(13)70214-X, indexed in Pubmed: 24012372.

15. Finsterer J, Wahbi K. CNS-disease affecting the heart: brainheart disorders. J Neurol Sci. 2014; 345(1-2): 8-14, doi: 10.1016/j. jns.2014.07.003, indexed in Pubmed: 25034054.

16. Priori SG, Aliot E, Blømstrom-Lundqvist C, et al. Task Force on Sudden Cardiac Death of the European Society of Cardiology. Eur Heart J. 2001; 22(16): 1374-1450, doi: 10.1053/euhj.2001.2824, indexed in Pubmed: 11482917.

17. Devinsky O. Effects of seizures on autonomic and cardiovascular function. Epilepsy Curr . 2004; 4(2): x43-46, doi: 10.1111/j.15357597.2004.42001.x.
18. Ravindran K, Powell KL, Todaro M, et al. The pathophysiology of cardiac dysfunction in epilepsy. Epilepsy Res. 2016; 127: 19-29, doi: 10.1016/j.eplepsyres.2016.08.007, indexed in Pubmed: 27544485 .

19. Powell KL, Jones NC, Kennard JT, et al. HCN channelopathy and cardiac electrophysiologic dysfunction in genetic and acquired rat epilepsy models. Epilepsia. 2014; 55(4): 609-620, doi: 10.1111/ epi.12563, indexed in Pubmed: 24592881.

20. Stöllberger C, Finsterer J. Cardiorespiratory findings in sudden unexplained/unexpected death in epilepsy (SUDEP). Epilepsy Res. 2004; 59(1): 51-60, doi: 10.1016/j.eplepsyres.2004.03.008, indexed in Pubmed: 15135167.

21. Elger CE, Schmidt D. Modern management of epilepsy: a practical approach. Epilepsy Behav. 2008; 12(4): 501-539, doi: 10.1016/j.yebeh.2008.01.003, indexed in Pubmed: 18314396.

22. Williams B, Mancia G, Spiering W, et al. 2018 ESC / ESH Guidelines for the management of arterial hypertension. ; 2018: 1-98.

23. Yoon SS, Carroll MD, Fryar CD. Hypertension prevalence and control among adults: United States, 2011-2014. NCHS Data Brief. 2015; 220: 1-8, indexed in Pubmed: 26633197.

24. De Venecia T, Lu M, Figueredo VM. Hypertension in young adults. Postgrad Med. 2016; 128(2): 201-207, doi: 10.1080/00325481.2016.1147927, indexed in Pubmed: 26821528.

25. Iwanami J, Mogi M, Iwai M, et al. Inhibition of the renin-angiotensin system and target organ protection. Hypertens Res. 2009; 32(4): 229-237, doi: 10.1038/hr.2009.5, indexed in Pubmed: 19262496.

26. Stupin A, Drenjancevic I, Rasic L, et al. A cross-talk between the renin-angiotensin and adrenergic systems in cardiovascular health and disease. Southeast Eur Med J. 2017; 1(1): 90-107.

27. Neves MF, Cunha AR, Cunha MR, et al. The role of renin-angiotensin-aldosterone system and its new components in arterial stiffness and vascular aging. High Blood Press Cardiovasc Prev. 2018; 25(2): 137-145, doi: 10.1007/s40292-018-0252-5, indexed in Pubmed: 29476451.

28. Grassi G, Allyn M, Murray E, et al. The Sympathetic Nervous System alteration in human hypertension. 2016; 116(6): 976-90.

29. Tsuda K. Renin-Angiotensin system and sympathetic neurotransmitter release in the central nervous system of hypertension. Int J Hypertens. 2012; 2012: 474870, doi: 10.1155/2012/474870, indexed in Pubmed: 23227311.

30. Wilner AN, Sharma BK, Soucy A, et al. Common comorbidities in women and men with epilepsy and the relationship between number of comorbidities and health plan paid costs in 2010. Epilepsy Behav. 2014; 32: 15-20, doi: 10.1016/j.yebeh.2013.12.032, indexed in Pubmed: 24463303.

31. Tchekalarova JD, Ivanova N, Atanasova D, et al. Long-term treatment with losartan attenuates seizure activity and neuronal damage without affecting behavioral changes in a model of co-morbid hypertension and epilepsy. Cell Mol Neurobiol. 2016; 36(6): 927-941, doi: 10.1007/s10571-015-0278-3, indexed in Pubmed: 26464042.

32. Tchekalarova J, Loyens E, Smolders I. Effects of AT1 receptor antagonism on kainate-induced seizures and concomitant changes in hippocampal extracellular noradrenaline, serotonin, and dopamine levels in Wistar-Kyoto and spontaneously hypertensive rats. Epilepsy Behav. 2015; 46: 66-71, doi: 10.1016/j. yebeh.2015.03.021, indexed in Pubmed: 25922088. 
33. McKinley MJ, Albiston AL, Allen AM, et al. The brain reninangiotensin system: location and physiological roles. Int J Biochem Cell Biol. 2003; 35(6): 901-918, doi: 10.1016/s13572725(02)00306-0, indexed in Pubmed: 12676175.

34. Pereira MG, Souza LL, Becari C, et al. Angiotensin II-independent angiotensin-(1-7) formation in rat hippocampus: involvement of thimet oligopeptidase. Hypertension. 2013; 62(5): 879-885, doi: 10.1161/HYPERTENSIONAHA.113.01613, indexed in Pubmed: 24041943.

35. Wright JW, Harding JW. The brain renin-angiotensin system: a diversity of functions and implications for CNS diseases. Pflugers Arch. 2013; 465(1): 133-151, doi: 10.1007/s00424-0121102-2, indexed in Pubmed: 22535332.

36. Saavedra JM, Sánchez-Lemus E, Benicky J. Blockade of brain angiotensin II AT1 receptors ameliorates stress, anxiety, brain inflammation and ischemia: Therapeutic implications. Psychoneuroendocrinology. 2011; 36(1): 1-18, doi: 10.1016/j.psyneuen.2010.10.001, indexed in Pubmed: 21035950.
37. De Bundel D, Smolders I, Vanderheyden P, et al. Ang II and Ang IV: unraveling the mechanism of action on synaptic plasticity, memory, and epilepsy. CNS Neurosci Ther. 2008; 14(4): 315-339, doi: 10.1111/j.1755-5949.2008.00057.x, indexed in Pubmed: 19040556.

38. Ibrahim MA, Koorbanally NA, Islam MS. In vitro anti-oxidative activities of the various parts of Parkia biglobosa and GC-MS analysis of extracts with high activity. Afr J Tradit Complement Altern Med [Internet]. Afr J Tradit Complement Altern Med. 2013; 10(5): 283-291.

39. Bar-Klein G, Cacheaux LP, Kamintsky L, et al. Losartan prevents acquired epilepsy via TGF- $\beta$ signaling suppression. Ann Neurol. 2014; 75(6): 864-875, doi: 10.1002/ana.24147, indexed in Pubmed: 24659129.

40. Gouveia TL, Frangiotti MI, de Brito JM, et al. The levels of renin-angiotensin related components are modified in the hippocampus of rats submitted to pilocarpine model of epilepsy. Neurochem Int. 2012; 61(1): 54-62, doi: 10.1016/j.neuint.2012.04.012, indexed in Pubmed: 22542773. 